\title{
LAS MÉDULAS (LEÓN), UN PAISAJE CULTURAL PATRIMONIO DE LA HUMANIDAD
}

\author{
LAS MÉDULAS (LEÓN), A CULTURAL LANDSCAPE AND WORLD HERITAGE SITE
}

F.-JAVIER SÁNCHEZ-PALENCIA $(*)$

M. ${ }^{\mathrm{a}}$ DOLORES FERNÁNDEZ-POSSE $(* *)$

JULIO FERNÁNDEZ MANZANO $(* * *)$

ALMUDENA OREJAS (*)

LUIS CARLOS PÉREZ $(* * * *)$

INÉS SASTRE $(*)$

\section{RESUMEN}

El proyecto de investigación de la Zona Arqueológica de Las Médulas (León) se ha realizado desde una perspectiva científica y patrimonial que valorase su comprensión como un paisaje cultural, resultando a su vez de un proceso histórico. En este artículo se analizan los presupuestos y condicionantes de esa concepción, los criterios que permiten llegar a esa valoración y las medidas concretas tomadas hasta ahora para su conversión en Parque Arqueológico, como proyección social de la labor investigadora.

\section{ABSTRACT}

The research project of the Archaeological Zone of Las Médulas (León) was developed from a scientific and heritage related approach that stressed its understanding as a cultural landscape which results from a historical process. In this paper the premises and determinants of that view are analised, together with the criteria for that valuation and the particular measures already taken for its conversion into an Archaeological Park, as a social outcome of the research work.

(*) Dpto. de Historia Antigua y Arqueología, Instituto de Historia del CSIC. Duque de Medinaceli, 6. 28014 Madrid. Correo electrónico: jspalencia@ceh.csic.es

(**) Dpto. de Monumentos y Arqueología, Instituto del Patrimonio Histórico Español. Greco, s/n. 28040 Madrid.

(***) Dpto. de Prehistoria y Arqueología, Universidad de Valladolid. Plaza del Campus, s/n. 47011 Valladolid.

(****) Sociedad Española de Talcos. Herminio Rodríguez, s/n. 24850 Boñar. León.

El artículo fue remitido en su versión final el 18-X-2000.
Palabras clave: Paisajes y Parques Culturales. Arqueología del Paisaje. Cultura Castreña. Minería Romana. Noroeste de la Península Ibérica.

Key words: Cultural Landscapes and Parks. Landscape Archaeology. Castreña (Hillforts) Culture. Roman Mining. Northwest of Iberian Peninsula.

\section{EL PROYECTO}

El equipo de investigación que firma este trabajo lleva ya más de una década dedicado a la investigación y valoración de los paisajes culturales y en particular de la Zona Arqueológica de Las Médulas (ZAM) como Paisaje Cultural (1). Las Médulas poseía ya un reconocimiento como bien de interés cultural (BIC), basado sobre todo en las estructuras visibles de lo que fue la mina de oro romana (2).

(1) Los trabajos llevados a cabo en la ZAM han sido posibles gracias a una serie de proyectos realizados o coordinados desde el Dpto. de Historia Antigua y Arqueología del Instituto de Historia del CSIC (Madrid): Zona Arqueológica de Las Médulas (ZAM) (Dir. Gral. de Patrimonio y Promoción Cultural de la Junta de Castilla y León, 1988 - 1996); Estudio de viabilidad de la ZAM como Parque Arqueológico (Instituto del Patrimonio Histórico Español del MEC, 1991); Paisajes Antiguos en la Península Ibérica: Arqueología y Textos (Paisat I), PB94/0125 de la DGICYT del MEC (1995-1998) y Paisajes Antiguos en la Península Ibérica. Teoría y Práctica de la Arqueología del Paisaje (Paisat II), PB97/1129 de la SEUID del MEC (1998-2001). Además de los autores firmantes, más de una decena de investigadores han contribuido sustantivamente en la consecución de resultados y cumplimiento de objetivos; a todos ellos, a quienes resultaría muy prolijo citar ahora, queremos expresarles nuestro más sincero agradecimiento.

(2) Fueron sin duda los espectaculares vestigios de la mina de oro romana los que propiciaron su inclusión dentro de la famosa y numerosa lista de Monumentos Histórico-Artísticos declarados como tales a escala nacional a comienzos de la II República (Decreto de 3 de junio de 1931, Gac. 04.06.31). 


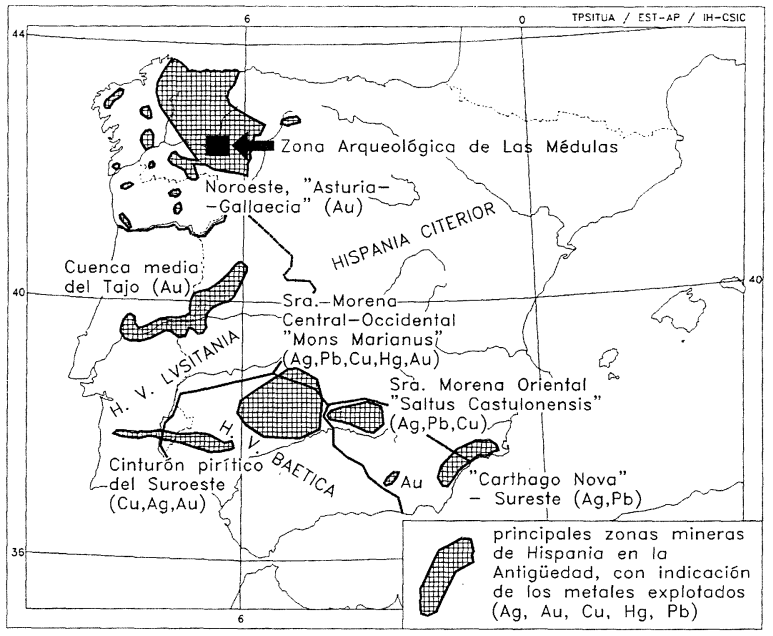

Fig. 1. Las Médulas y las principales zonas mineras de Hispania.

Como decía un cartel allí instalado era considerada un "monumento de la ingeniería romana". Esa apreciación capitalizó casi absolutamente la valoración científica y patrimonial de la zona hasta los años 80 . Nuestro trabajó pretendió desde sus inicios superar esa visión sectorial y creemos que ha contribuido notablemente a potenciar su revalorización desde una perspectiva más integral, considerándolo como un paisaje cultural resultado de un proceso histórico muy complejo y que excede sin duda su importancia estrictamente tecnológica.

Aunque teóricamente la cadena investigaciónvaloración-difusión debe presidir la estrategia de las actuaciones sobre este tipo de BIC, su desarrollo no siempre puede seguir esa dirección tan lineal; es más, en casi todos los casos resulta imprescindible proceder de forma escalonada y compaginar esos tres objetivos de forma complementaria. Así ha ocurrido en el caso de Las Médulas, donde ha sido imprescindible ir combinando avances en los tres campos mencionados hasta alcanzar los resultados actuales. De cualquier forma y a efectos instrumentales, en la exposición que sigue sí vamos a articular nuestro discurso de acuerdo con ese orden.

A lo largo de esa década hemos intentado basar todas nuestras intervenciones en las nuevas tendencias agrupables dentro de laArqueología del Paisaje, que persigue entre sus objetivos dotar, no sólo a la disciplina, sino también al patrimonio arqueológico de una mayor dimensión espacial y territorial. Esos nuevos enfoques nos han servido para reforzar y ampliar el alcance patrimonial de nuestra actividad.

T. P., 57, n. ${ }^{\circ} 2,2000$
Esta perspectiva no es ajena por lo tanto a un replanteamiento del alcance y la proyección social que debe presidir nuestra labor investigadora y científica como arqueólogos e historiadores que, sobre todo cuando se realiza desde instituciones públicas, debe ser considerado como un objetivo prioritario. En el marco de este número monográfico de $T P$, creemos necesario resaltar la importancia que tiene un compromiso al respecto de los profesionales de laArqueología. A través de la prensa diaria puede comprobarse que cada vez son más frecuentes las iniciativas de explotación como recurso de nuestro Patrimonio, realizadas casi siempre desde una concepción del "mercado cultural" estrictamente, valga la redundancia, mercantil en el que la cultura, con minúscula, es más un medio que un objetivo. Tales iniciativas sobrepasan muchas veces al ámbito estrictamente patrimonial y responden a unas orientaciones de política económica casi inabordables desde las instancias profesionales e institucionales de la Arqueología. Pero también es cierto que aun existen muchas reticencias desde nuestro propio campo a la hora de comprometerse en intervenciones concretas sobre el Patrimonio Arqueológico como recurso, es decir, en actuar para intentar cambiar las bases estructurales de tal mercado y adecuarlas a los notables avances teóricos y sociales producidos en la concepción, valoración y difusión del Patrimonio Histórico y Arqueológico.

\section{LA IDENTIDAD PATRIMONIAL DE LAS MÉDULAS Y EL CONCEPTO DE PAISAJE CULTURAL}

Cuando decíamos antes que Las Médulas poseía ya desde hace tiempo un reconocimiento de su valor nos referíamos a los evidentes y espectaculares restos de la mina de oro romana más grande de todo el Imperio Romano (Fig. 1). La mina de oro supuso la remoción de casi 100 millones de $\mathrm{m}^{3}$ de tierra, mide unos $3 \mathrm{~km}$ de anchura máxima, sobrepasa los $100 \mathrm{~m}$ de profundidad en el sector más extenso de los tres excavados y las transformaciones que causó afectan a unas 1200 ha. Esa notable intervención humana se produjo sobre unos depósitos de conglomerados miocenos de un intenso color rojo que forman el yacimiento aurífero y están colgados sobre su entorno inmediato, de forma que los desmontes resaltan en la actualidad con sus picuezos y frentes escarpados la alteración topográfica producida. La mina adquiere por derecho propio una 
posición central y un protagonismo fuera de toda duda que siempre ha llamado poderosamente la atención de quienes la contemplan (3).

Pero también existe el peligro de dejarse atrapar por su excepcionalidad como testigo de una actividad productiva hoy considerada sectorial y olvidarse de lo que esa minería del oro supuso en unos términos históricos más amplios y, sobre todo, en su impacto sobre las estructuras territoriales y sociales de la zona y las comunidades que la ocupaban. En último término, nos estamos refiriendo al peligro de mitificar Las Médulas.

El camino recorrido desde ese cuasi mito histórico hasta su consideración como paisaje cultural (Sánchez-Palencia et alii, 1999: 13-19) se inserta, por un lado, dentro de la evolución que ha experimentado en las últimas décadas el concepto de $\mathrm{Pa}$ trimonio Histórico, influido e influyente en la creciente valoración del Paisaje (no simplemente el medio ambiente) como un elemento muy importante dentro de las condiciones de la calidad de la vida. Además, y sobre todo en nuestro caso, hay que entender esa evolución desde los nuevos enfoques que se han incorporado en la propia actividad disciplinar de la Arqueología.

Los cambios en la disciplina arqueológica han afectado tanto a sus fundamentos teóricos como a los enfoques que informan su investigación, cada vez más ecológicos, antropológicos y sociales. Paralelamente y como consecuencia de ellos, se han perfeccionado nuevos métodos y técnicas instrumentales, incorporados ya plenamente tras una primera fase de interdisciplinaridad. No es ésta la ocasión de entrar a pormenorizar esos cambios (4), pero sí de resaltar algunos de ellos y considerar en particular la incidencia que han tenido en la protección, valoración y difusión del patrimonio arqueológico, puesto que han informado nuestros planteamientos en el caso concreto de la ZAM:

- El abandono de los enfoques arqueológicos que primaban un patrimonio de valores muy explí-

(3) Un ejemplo muy ilustrativo son las palabras del novelista romántico berciano Gil y Carrasco (1985: 87): "una montaña de la más caprichosa forma que imaginarse pueda (...) de un encarnado vivo y crudo y coronada por picachos y torreones del mismo color, (...) nada tiene de común con los montes circunvecinos; y se asemeja a un monumento levantado por la mano de una raza de gigantes, ..." Sobre la contribución "cultista" a la valoración histórica de Las Médulas y otros aspectos relacionados con la visión que han transmitido de ella los escritores ilustrados y románticos: Olmos (e.p.)

(4) Sobre la historiográfica de los estudios de arqueominería: Domergue, 1986 y Orejas et alii, 1999. Sobre la incidencia de los mencionados cambios en el proyecto ZAM: Sánchez-Palencia et alii, 1996. citos y evidentes, en el que lo importante eran los hallazgos, lo monumental, etc, lo que podríamos definir como una arqueología objetual. Si un yacimiento podía ser valorado y visitable in situ era porque no podía trasladarse al museo. De tal visión procede la expresión de la musealización de un yacimiento, tan popular como inapropiada por la contradicción intrínseca que implica. Prueba de ello es que las iniciativas de arqueologías visitables se apoyaban más en la entidad física de las estructuras recuperadas que en el trabajo desarrollado para su adecuación y explicación, y dejaban fuera, por ejemplo, manifestaciones arqueológicas cuya apariencia visible fuese modesta o escasa tras la excavación.

- En contraposición con lo anterior, se ha producido una clara y creciente incorporación del espacio. Tras una arqueología basada en las secuencias y cronologías de los hallazgos, puesto que el tiempo era el factor articulador de la investigación, se ha pasado al medio físico, al contexto, a los procesos, al territorio, a los comportamientos económicos, sociales o simbólicos y a la arqueología del paisaje (5).

- La situación del PatrimonioArqueológico en la realidad actual dentro de esa nueva manera de entender la cultura provocada, al menos en occidente, por su demanda social, que está acercando cada vez más el concepto de cultura al de entretenimiento y propiciando la consideración del Patrimonio como recurso y, por tanto, explotable económicamente. Eso nos ha obligado a los arqueólogos a plantearnos la utilidad y rentabilidad del objeto de nuestra investigación y a llegar a la conclusión de que una actuación arqueológica no se justifica sin una proyección social.

Este último es seguramente el aspecto más conflictivo, ya que hace entrar al Patrimonio Arqueológico en una ambigua situación de búsqueda de equilibrio: compaginar su valoración como BIC de gran interés investigador y formativo con el de su rentabilidad con un cierto carácter lúdico. Se añade a ello el agravante de ser un tipo de patrimonio difícil de hacer comprender a un público no especializado, que en su parcialidad documental necesita de una interpretación o un intermediario, porque han de serle aplicados unos criterios de intervención, con el eterno debate entre conservacio-

(5) Sobre la diversidad de enfoques que se pueden adoptar desde la Arqueología del Paisaje pueden consultarse los trabajos reunidos bajo la coordinación de F. Burillo (1998). 
nistas y reconstructivistas, por su falta de funcionalidad explícita, etc.

Pero de igual forma que a los museos hoy se les pide que expongan conceptos y no solamente objetos, para comenzar a hablar de la explotación, sea cultural, social o económica, del Patrimonio Arqueológico, ha de haber una previa y completa investigación. Nada más falaz en este caso que contraponer ambos aspectos, y ahí se ve bien el carácter de ciencia de la disciplina; en Arqueología no se llega a una buena divulgación si no es tras un profundo trabajo de investigación.

Esa explotación de la que es susceptible el Patrimonio Arqueológico, como factor de desarrollo local o comarcal dentro del llamado turismo cultural y de naturaleza, lo somete sin embargo a las limitaciones de todo recurso no renovable: pérdida de autenticidad cuando entra de lleno en la cultura del simulacro o necesidad de aplicarle estrategias del tipo de desarrollo duradero cuando se pone en peligro su conservación. No hace tantos años se reivindicaba para él una rentabilidad social, ahora también se le exige una rentabilidad económica.

La realización de nuestro proyecto de investigación y valoración desde los presupuestos hasta aquí mencionados contribuyó a que cuando, en 1997, la ZAM fue declarada Patrimonio Mundial o de la Humanidad por la UNESCO, lo fuera como un tipo de bienes determinados que son los Paisajes Culturales. Esta categoría que establece la propia UNES$\mathrm{CO}$, quizás de forma un poco rígida como en casi todas las clasificaciones, para los que podrían denominarse arqueológicos, se define como el paisaje que ha experimentado un proceso evolutivo que se ha detenido en un cierto momento del pasado, súbitamente o a lo largo de una etapa de mayor duración, y cuyas características esenciales han quedado materialmente visibles. Se denomina también paisaje relicto o fósil y forma parte de una categoría mayor que son los paisajes evolutivos, considerados como el resultado que han producido determinados factores sociales, económicos, políticos, etc en un determinado medio natural. Son un tipo de paisajes que con frecuencia permanecen vivos. Todas estas tipologías entran, por otro lado, dentro de una definición más general que cubre la gran variedad de manifestaciones interactivas entre la humanidad y su entorno natural (6). También es coinci-

(6) UNESCO: Comité Intergouvernemental pour la Protection du Patrimoine Mondial Culturel et Naturel. Orientations devant guider la mise en oeuvre de la Convention du patrimoine mondial. WHC-97/2/Revisé. Paris. Février. 1997, 9-10. dente con la definición de Paisaje que ha propuesto más recientemente el comité de expertos del Consejo de Europa para la Convención Europea del Paisaje: "designa una parte del territorio según es percibido por sus poblaciones, cuyas ceracterísticas son el resultado de la acción de factores naturales y/o humanos y de sus interrelaciones" (7). En este último caso se añade a la valoración el componente cognoscitivo de la población de la zona, sin el que sería imposible su reconocimiento actual.

\section{LA REPRESENTATIVIDAD DE LAS MÉDULAS COMO PAISAJE CULTURAL}

Siguiendo los criterios expuestos y a condición de que sean acordes con los planteamientos teóricos y metodológicos de la investigación y con la viabilidad de su planificación y gestión, los Paisajes Culturales deben cumplir otras exigencias para serlo verdaderamente. Vamos a intentar exponerlas a continuación sobre el ejemplo concreto de la ZAM.

Siempre es difícil intentar definir unos criterios que permitan resaltar el interés que posee un determinado paisaje cultural para ser destacado como tal, es decir, para que sea representativo. No creemos posible la elaboración de una clasificación cuantificable en tal sentido. Por su propio carácter este tipo de bienes culturales deben valorarse de acuerdo con unos criterios relativamente abstractos, que se concretan a través de su capacidad para sintetizar su relevancia en un amplio marco histórico y geográfico. La propuesta realizada en la revista Antiquity por un equipo que ha estudiado este tipo de criterios sobre el patrimonio inglés (Darvillet alii, 1993) nos parece que ha sido una de las más acertadas. Se trata, insistimos, de factores de evaluación netamente contextuales e indisociables del espacio y de los procesos históricos en los que se insertan. Son también

(7) T-LAND (2000) 2, 10: Project de convention européenne du Paysage. Comité Restreint d'experts chargé de la redaction de la Convention Européenne du Paysage. Conseil de l'Europe. Strasbourg, 23 fevrier 2000, Cap. I, $\operatorname{art}^{\circ} 1$,a. En relación con esta misma cuestión: ECP Archaeological Heritage (1992): European Convention on the Protection of the Archaeological Heritage (revised). Valletta 16.I.1992. European Treaty Series. 143; CC-PAT (93) 10: Reunión de especialistas sobre "Sitios" y paisajes culturales. Strasbourg, 3-5 de Febrero de 1993. Informe de la Reunión. 18 de Febrero de 1993 (Traducción); CC-PAT (93) 80, REvisÉ 2: Comité du Patrimoine Culturel. Groupe de Spécialistes sur les sites et paysages culturels. Proposition de Recommandation aux États membres relative a la conservation des Sites Culturels integrée aux politiques du paysage. Conseil de l'Europe. Strasbourg, 10 février 1994

T. P., 57, n. $^{\circ} 2,2000$ 
factores no jararquizables y que han de considerarse como interactuantes entre sí.

Ya hemos dicho que Las Médulas es un BIC que supera claramente al monumento técnico que es la mina, pero tampoco es una agrupación o conjunto de elementos patrimoniales más o menos relacionados entre sí. En primer lugar porque el territorio que comprende conforma una auténticaunidad geomorfológica e histórica.

Desde el punto de vista geomorfológico, la ZAM se sitúa en el espacio que ocupa una de las tres cubetas que forman la depresión berciana. Materialmente se puede delimitar mediante unos límites muy claros y concretos (Fig. 2). Hacia el norte y el oeste está definida por el curso del río Sil y hacia el sur por su afluente el Cabrera. Por el este permanece unida a los Montes Aquilianos por medio de nervaduras montañosas, de forma que hacia ese lado es el tránsito desde los depósitos aluviales del yacimiento aurífero a los escarpes montañosos el único límite posible.

Ocupando el centro de esa unidad está la mina de oro (Fig. 3) que, como ya dijimos, domina como principal protagonista histórico todo el paisaje, más que por su vistosidad o sus dimensiones, por las transformaciones de la actividad minera. Además de los desmontes, que supusieron la remoción a lo largo de casi 200 años (siglos I y II d.C. en líneas generales) de unos 93,55 millones de $\mathrm{m}^{3}$ en más de 500 ha, los estériles generados rellenaron casi 600 ha de los antiguos valles y vaguadas. De hecho, de las 12000 ha de terreno que hemos investigado una décima parte son de origen romano. Es más, la mayor cola de lavado o cono de deyección de esos estériles, Chaos de Maseiros, llegó a taponar un valle y dió lugar a la aparición del Lago de Carucedo, que es por ello de origen romano, pero de formación no intencional.

La actividad minera desmanteló por lo tanto el yacimiento aurífero mioceno colgado dentro de la cubeta, pero acentuó la unidad del nuevo paisaje estableciendo claros nexos de unión de entidad topográfica entre las cotas más altas y las más bajas de la zona, desde los frentes de explotación más elevados, sobre los $1000 \mathrm{~m}$ de altura, hasta el final de las colas de lavado, por debajo de los 500 $\mathrm{m}$. Queremos resaltar que el resultado, ese paisaje minero, no permaneció simplemente fosilizado sino que fue utilizado posteriormente en sus diversos elementos como un nuevo factor de vertebración del espacio. Sobre la nueva superficie creada en el fondo del principal sector se habilitaría con el

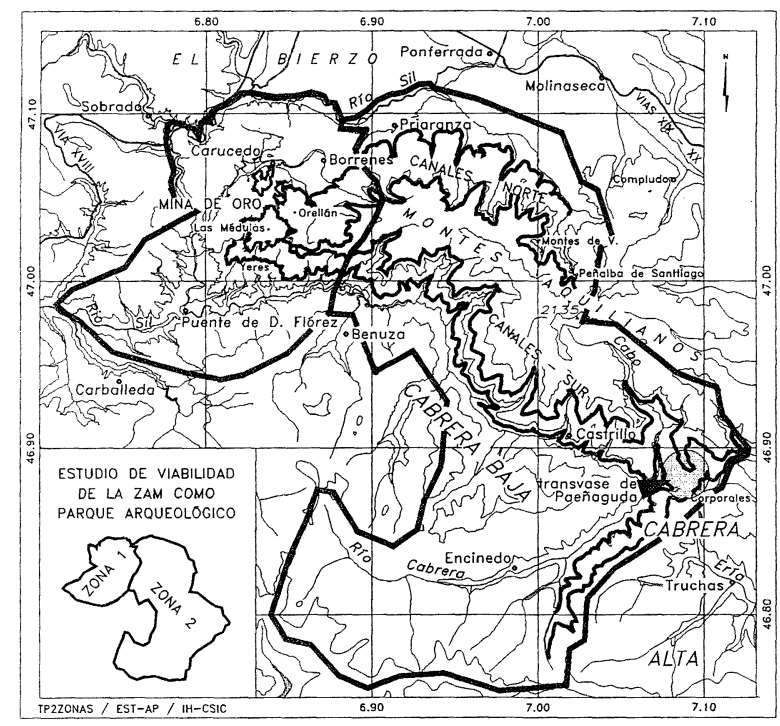

Fig. 2. Las dos zonas propuestas de delimitación de la Zona Arqueológica de Las Médulas según figuraban en el estudio de viabilidad como Parque Arqueológico.

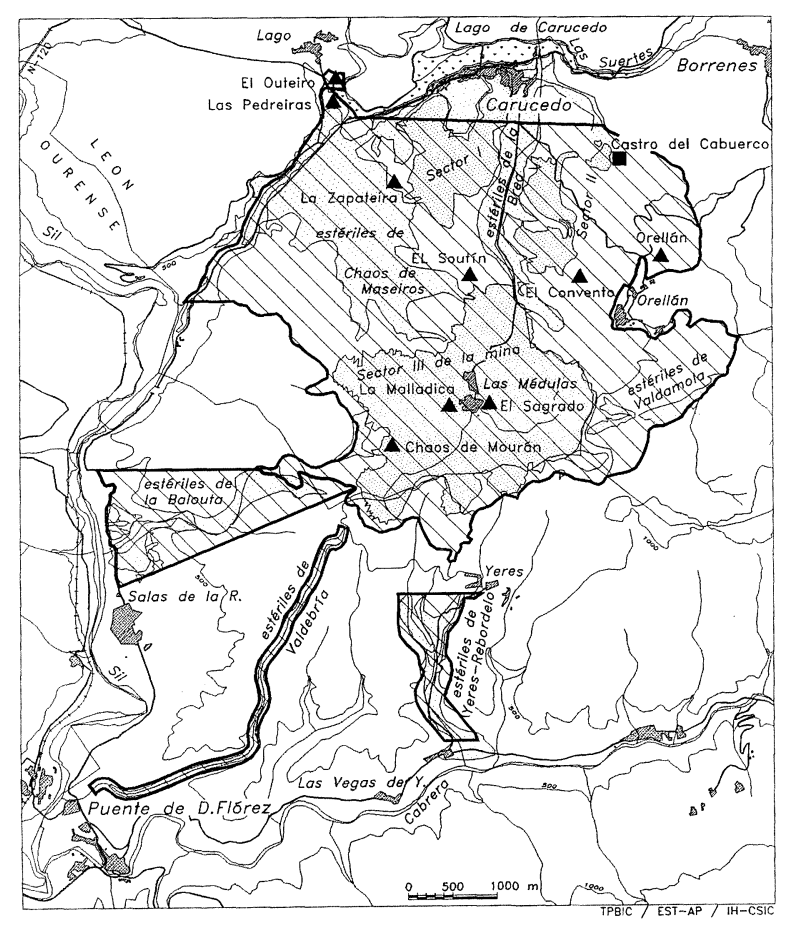

Fig. 3. Delimitación de la Zona Arqueológica de Las Médulas como Bien de Interés Cultural, la misma que figura en el expediente del Patrimonio de la Humanidad.

paso del tiempo el terrazgo del propio pueblo de Las Médulas. Las colas de lavado con estériles de La Brea, La Balouta o Yeres-Rebordelo facilitaron 


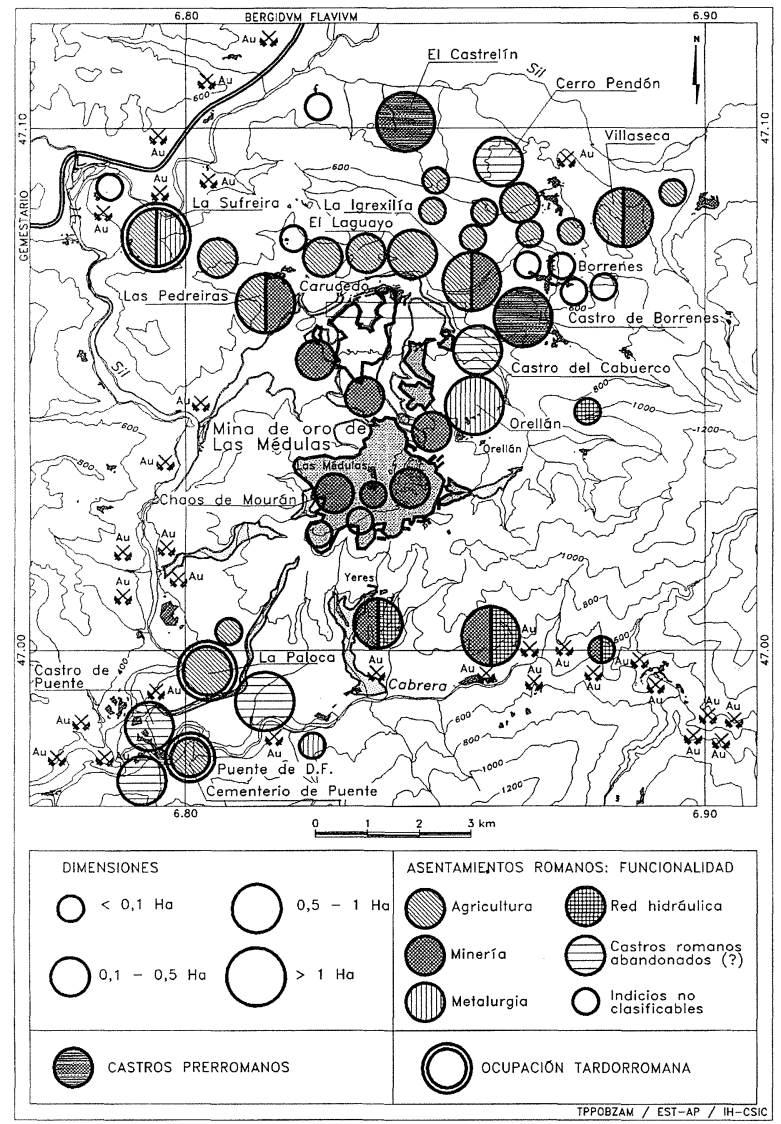

Fig. 4. Yacimiento de la ZonaArqueológica de Las Médulas (León) y tendencias en la ocupación del territorio.

también el acceso a través de los antiguos y encajados valles que rellenaron. La progresiva colmatación del nuevo lago de Carucedo proporcionó las mejores tierras de cultivo, Las Suertes, para el pueblo de Borrenes. En fin, los cauces de los canales romanos, que bordean por sendas vertientes los MontesAquilianos, han servido de carriles o caminos de comunicación para la población y los ganados hasta no hace mucho.

Dentro de esa unidad, otro de los criterios que definen estructuralmente a este paisaje es la clara articulación de todos los elementos que testimonian la ocupación y explotación antigua en torno a esas evidencias de origen minero. Entre ellos están los provocados por la explotación del resto de los recursos naturales, incluido el propio suelo, y los asentamientos. Todos ellos responden a un esquema de apropiación y ordenación del espacio, tanto de esa unidad morfológica como de otras zonas adyacentes más extensas, como es el espacio ocupado por la infraestructura hidráulica que llega a alcanzar hacia el este $100 \mathrm{~km}$ de recorrido (Fig. 2). Se trata por lo tanto de un planeamiento global de la zona y de las comunidades que lo ocupaban por parte de los romanos, que generó morfologías específicas, formas de producción, red de comunicaciones, centros de poder, etc; en definitiva que jerarquizó ese territorio. Se cumple de esta forma otro de los criterios que definen el Paisaje Cultural: la integración de todos sus elementos.

Esta integración, así como la medida de esa transformación romana en el paisaje adquiere una mayor dimensión cuando se comparan sus elementos con los de la ocupación prerromana (Fig. 4). En efecto, las poblaciones anteriores a la presencia romana se vertebran en torno a castros separados por distancias desiguales, que buscan sus emplazamientos en función de terrenos propicios para su economía campesina autosuficiente. Se trata de comunidades reducidas, de unos 150-200 habitantes, nuclearizadas en asentamientos de no más de una hectárea de extensión. Su dominio territorial se reduce a las tierras de labor y a otras unidades productivas, situadas todas en el entorno inmediato al poblado.

El contraste entre ambas maneras de ocupar el mismo territorio entre época prerromana y romana, permite evaluar el grado de articulación e integración que proporciona la mina por encima de su indudable atracción visual.Y ese potencial es precisamente el que se utiliza desde la guía y el aula arqueológica (a las que luego nos referiremos) para que, una vez provocada la atención del visitante, su curiosidad trascienda y para que a través de los itinerarios que se le ofertan entienda el Paisaje de forma global y con una perspectiva histórica. Tal contraposición es por lo tanto capital en todo el montaje didáctico.

Para llegar a este tipo de resultados, es necesario tener en cuenta que cuando se analiza un paisaje arqueológico se está ante una graduación de los diversos elementos que lo componen por su relación entre contenido y forma, es decir, unos son más evidentes que otros. En las labores mineras o en los canales esa relación es clara, pero no se deben olvidar aquellos elementos cuyas formas son difícilmente reconocibles. En el proyecto hemos prestado especial atención a la documentación de la diversidad de recursos que esa actividad minera propició, a la imprescindible existencia de una infraestructura que posibilitase esa ordenación global del territorio y la actividad minera llevada a cabo en la escala de Las Médulas. 
De esa forma, a partir del registro arqueológico y paleoecológico se llega a definir los terrenos de cultivo y el tipo de asentamiento a ellos asociados (Fig. 4). Aunque pueda resultar más costoso de comprender, es esencial explicar la puesta en valor de tierras de cultivo en la zona de La Campañana y Borrenes o de Salas de la Ribera y Puente de Domingo Flórez, donde se concentró buena parte de la producción agraria romana mediante pequeñas granjas. Este tipo de datos es esencial para no caer en una visión modernizante y sectorial de la ocupación romana, que sería distorsionante y anacrónica. De la misma forma, es preciso destacar la importancia de la metalurgia del hierro y sus factorías, donde se manufacturaban las herramientas y útiles, mineros o no, para toda la zona, según han puesto de relieve las excavaciones del asentamiento de Orellán, poblado por una mano de obra especializada, es decir, con una tendencia económica o funcionalidad muy clara. La construcción y mantenimiento de la infraestructura hidráulica también requirió el establecimiento de un sistema de pequeños castros de tipo romano y especialmente adaptados al terreno por donde circulan los canales que lo jalonan, ya analizados en parte en un estudio anterior (SánchezPalencia y Fernández-Posse, 1985 y FernándezPosse y Sánchez-Palencia, 1988). También se han documentado los poblados destinados al alojamiento de la mano de obra más específicamente vinculada al trabajo minero y asentada a veces en el interior de la mina, después de explotada, así como aquellos otros desde donde se producía el control técnico y administrativo, como es el caso del asentamiento de Las Pedreiras, donde se establece desde el principio de los trabajos un grupo de población altamente romanizada, como corresponde a una mano de obra especializada capaz de controlar la organización y de dar soporte técnico a la minería del oro.

Esta enumeración, que no pretende ser exhaustiva, es buena muestra de la diversidad que debe tener, como otro criterio esencial de valoración, un Paisaje Cultural. Diversidad que se potencia, una vez más, con la de los dos castros prerromanos excavados, que cubre bien los siglos anteriores al cambio de Era (El Castrelín) o bien el momento de contacto de esas comunidades indígenas con los romanos (El Castro de Borrenes).

Tal diversidad se vertebra en el diseño del Parque con varios itinerarios donde quedan bien de manifiesto las diferencias de las dos ocupaciones, la prerromana y la romana y su proceso de ruptura. De igual forma los dos asentamientos de época romana elegidos para que sean visitados pretenden ofrecer al visitante el marcado contraste entre las formas de vida de la mano de obra indígena y no cualificada del poblado metalúrgico de Orellán frente a los técnicos que habitaban la casa tan formalmente romana de Las Pedreiras. Esta estructura se refleja igualmente en el aula arqueológica, donde, a su vez, se le dota de una explicación histórica global que difícilmente es comprensible sobre el terreno.

Como ya hemos comentado, la ZAM, no es el único paisaje minero que dejaron los romanos en el Noroeste. La actividad aurífera romana dejó en esa región otros muchos ejemplos, entre los que algunos presentan el mismo buen estado de conservación y equiparable envergadura (quizás no en volumen, pero sí en extensión y otros parámetros) a la de Las Médulas. De igual forma, el proceso histórico desarrollado debió ser similar en esas otras zonas mineras, que incluye a más de medio millar de minas de oro e implicó la remoción de unos 900 millones de $\mathrm{m}^{3}$. Igualmente todos los elementos de carácter tecnológico (los sistemas de explotación selectivos o extensivos, por ejemplo) quedan bien representados en Las Médulas. Queda claro pues la calidad de modelo que puede atribuírsele.

Para terminar, ese valor paradigmático de la ZAM creemos que cumple mejor su función como Paisaje Cultural representativo, no sólo porque en ella todos los elementos están presentes y hayan sido documentados en el curso de nuestro proyecto con la diacronía y el detalle suficiente para comprender un proceso histórico, sino por su escala. En efecto, en la ZAM todos esos elementos y los factores que los conjugan y hacen de ellos una verdadera estructura, se reúnen en un marco idóneo de poco más de $10 \mathrm{~km}^{2}$ (Figs. 2 - 4). Este grado de concentración se manifiesta, tanto en sus propios términos cuantitativos espaciales, como a través de una excelente relación visual entre todos los elementos que constituyen el paisaje. Es decir, cuenta con unos puntos de visión panorámica que permiten al visitante aprehender esas condiciones de integración, articulación, diversidad y estructura que permiten afirmar que forma y contenido alcanzan un fuerte grado de relación.

¿En qué medida se ha visto reflejada de forma práctica la valoración de todos estos factores en la ZAM? La mejor contrastación al respecto es la consideración que ha merecido para ser incluida en la Lista del Patrimonio de la Humanidad. El propio comité de la UNESCO que preparó el expediente de 
evaluación para que esa inclusión se produjese en la reunión de Nápoles de diciembre de 1997 (8), se hizo eco de tales factores al reconocer que el paisaje antiguo de Las Médulas no sólo conservaba excepcionalmente los elementos industriales de la actividad minera, sino también los referidos a las comunidades que hicieron posible tal actividad, representados a través de los múltiples yacimientos excavados o por excavar. El mismo comité indica que Las Médulas se inscribía siguiendo cuatro de los criterios exigidos:

- Criterio $1^{\circ}$ : Ser una obra destacada de la creatividad humana, específicamente por la tecnología minera utilizada (se menciona la ruina montium y la importancia de la fuerza hidráulica) y por la importancia económica que tuvo para el Imperio Romano.

- Criterio $2^{\circ}$ : Proporcionar un testimonio destacado de la creación de un Paisaje Cultural, marcado por la importante intervención humana y los posteriores procesos naturales, mencionando en especial la introducción de nuevos cultivos (el castaño sería el más relevante por su huella en el paisaje actual) que han pervivido sin cambios desde época romana hasta hoy.

- Criterio $3^{\circ}$ : Constituir una evidencia única, o almenos excepcional, de un tipo de trabajo y de una explotación tecnológica y científica de la naturaleza correspondiente a una civilización extinguida.

- Criterio $4^{\circ}$ : Ser un ejemplo sin paralelos resultante de la unión entre Arqueología y Paisaje que ilustra un período de gran importancia para la Humanidad y para el sostenimiento económico del Imperio Romano durante los siglos I y II d.C.

\section{PROYECTO DE INVESTIGACIÓN Y PROYECCIÓN SOCIAL: LA CONVERSIÓN DE LA ZAM EN PARQUE}

Según los criterios del ya mencionado comité de expertos del Consejo de Europa, además e incluso por encima de su valoración histórica, es conveniente tener presente que el Paisaje debe comprenderse como el marco en el que vive una determinada comunidad y, en ese sentido, es indisociable de la noción de desarrollo duradero de la zona del que debe ser una expresión y un componente importan-

(8) UNESCO. World Heritage Convention. Bureau of The World Heritage Committee. 21th session (23-28 June 1997), Paris (France). Evaluation of Cultural Properties. Prepared by the International Council on Monuments and Sites (ICOMOS). te. Las valoraciones de carácter científico o profesional han de pasar por lo tanto a un segundo plano, por más que constituyan un punto de apoyo sustancial para la consecución de tales objetivos y la consideración del paisaje cultural como recurso debe ocupar un lugar preeminente (9). Para que tal hecho se produzca es necesario llevar a cabo una serie de actuaciones concretas, que en el caso de la ZAM se han articulado entorno a su conversión en Parque Arqueológico. Vamos a exponer a continuación cuál ha sido su génesis y desarrollo y en qué han consistido.

Los trabajos que han conducido a la materialización del Parque Arqueológico de Las Médulas se iniciaron cuando la Consejería de Cultura y Turismo de la Junta de Castilla y León, consciente de la importancia patrimonial de la ZAM y ante la afluencia creciente de visitas, se puso en contacto en 1989 con el Instituto de Conservación y Restauración de Bienes Culturales (actual Instituto del Patrimonio Histórico Español) para proyectar un parque dentro de una iniciativa que llegó a ser un Plan Nacional del Ministerio de Cultura (Parques, 1993) (10). Paralelamente, nuestro equipo estaba llevando a cabo desde 1988, según los objetivos ya expuestos, el proyecto de investigación en la zona, coordinado desde el Departamento de Historia Antigua y Arqueología del Centro de Estudios Históricos (hoy Instituto de Historia) del CSIC.

Como resultado de las dos anteriores circunstancias, nuestro equipo de investigación redactó un estudio de viabilidad para la conversión de la ZAM en Parque Arqueológico (11). Dado que dicho estudio no ha sido objeto de ninguna publicación hasta ahora, nos parece oportuno resumir a continuación su contenido:

1. Delimitación de la ZAM en cuanto que tal Zona Arqueológica, que dentro de las diferentes

(9) T-LAND (2000) 2, 10: Project de convention européenne du Paysage. Comité Restreint d'experts chargé de la redaction de la Convention Européenne du Paysage. Conseil de l'Europe. Strasbourg, 23 fevrier 2000, Cap. I, $\operatorname{art}^{\circ} 3$.

(10) En virtud de ese acuerdo, la Junta de Castilla y León seguiría financiando las investigaciones de campo según lo venía haciendo desde 1988 y el Ministerio de Cultura encargaría al mismo equipo de investigación la elaboración del estudio de viabilidad. Dado que ambas actuaciones podían desarrollarse dentro de los programas en curso de ambas instituciones, el acuerdo no necesitó ser plasmado por escrito.

(11) Sánchez-Palencia, F.J.; Fernández-Posse, MªD.; Fernández Manzano, J. (dir.), con la colaboración de Orejas, A.; Álvarez, Y.; López, L.F.; Pérez, L.C.; Báez Mezquita, J.; Jular, C. y Delibes, A. (1992a): La Zona Arqueológica de Las Médulas. Estudio de viabilidad para su conversión en Parque Arqueológico. ICRBC. Ministerio de Cultura. Madrid, junio de 1992. 301 pp. autoeditadas por ordenador con 142 figs. (inédito). 
figuras de BIC recogidos por la Ley $16 / 1985$ sobre el Patrimonio Histórico Español era la que más se ajustaba a su entidad (12). La declaración como monumento histórico-artístico de 1931 era sólo enunciativa y no había fijado de ninguna forma los límites del bien. Esta circunstancia que no es muy importante en el caso de los BIC fácilmente delimitables, sí presentaba y ha seguido presentando problemas en el caso de una zona tan amplia como ésta. En un principio se establecieron dos zonas, una primera y más importante que incluía al yacimiento y la mina de oro y su entorno más inmediato y una segunda que se definía esencialmente por la extensión de la infraestructura hidráulica (Fig. 2). Dejamos para un poco más adelante la discusión sobre estos límites, ciertamente conflictivos.

2. La parte esencial y más larga del estudio consistía en un análisis y valoración del Patrimonio Histórico en dos apartados: los componentes más destacados del Patrimonio Arqueológico, analizados cronológicamente desde los momentos prerromanos de la Cultura Castreña hasta la ocupación y explotación minera romana del territorio y las posibilidades de valoración de otros elementos de entidad histórica o de interés patrimonial (ordenación espacial de los núcleos rurales de la zona y determinas singularidades de su arquitectura vernácula).

3. El apartado dedicado al medio ambiente de la ZAM, además de analizar las características de los factores geomorfológicos del medio físico, la flora y la fauna, destacaba por razones obvias la importancia de la geología del yacimiento aurífero y también se detenía en el análisis de la población y los usos tradicionales del suelo.

4 y 5 . Las propuestas y el programa de actuaciones para la conversión en Parque Arqueológico de la ZAM incluía en primer lugar la imprescindible declaración delimitada del BIC. Su contenido fundamental era un anteproyecto para la articulación del parque a través de puntos de información e itinerarios, con un estudio y propuestas de actuaciones sobre las infraestructuras de acceso y servicios esenciales y un plan para proseguir las investigaciones aun no concluidas.

Este estudio de viabilidad tuvo dos consecuencias inmediatas principales. Por una parte sirvió para que los responsables autonómicos de la ZAM comprobasen que la zona se hallaba en un estadio

(12) Ley 16/1985 del Patrimonio Histórico Español, Título II, artículo 15,5 . de la investigación que permitía ya iniciar su conversión en parque (13), en segundo lugar suscitó un debate sobre la extensión e incidencia que podía tener en la zona la declaración del BIC según los límites propuestos. Ese debate se expresó sobre todo a través de declaraciones de prensa más que a través de una discusión concreta entre las partes interesadas.

El problema esencial de la declaración del BIC radicaba en la amplia extensión propuesta (Fig. 2), que se basaba precisamente en la consideración de toda la zona como un paisaje cultural, de forma que nos parecía absurdo renunciar a los principios defendidos y demostrados a la largo del proyecto de investigación. Por ejemplo y fijándonos sólo en los componentes patrimoniales más evidentes, los contemporáneos de la mina de oro romana, nos parecía anacrónico no incluir dentro de la declaración toda el área que afectaba a la red hidráulica y los asentamientos castreños romanos a ella asociados, que se hallaba dentro de la denominada zona 2. También nos parecía necesario acabar con la visión histórica sectorial de la actividad minera romana. Era necesario hacer comprender, desde la coherencia del proceso histórico al que respondía, que la ocupación y explotación del territorio supuso una puesta en valor de múltiples recursos, que la diferencia respecto a la ocupación prerromana radicaba precisamente en la introducción de una estructura de explotación a escala comarcal y regional antes inexistente. Hubiese resultado incluso deshonesto mantener dos discursos divergentes, uno científico y otro patrimonial.

Además del sobresalto que podría causar la declaración como BIC de una zona tan extensa, ya que afectaba a once municipios, existía un segundo e importante obstáculo. En buena parte de ese territorio se desarrolla una actividad industrial de gran impacto económico: las canteras de pizarra y, en menor medida, de caliza. Aunque nunca se llegó a una discusión abierta al respecto, ese problema latente pesó en la declaración. En realidad, el estudio simplemente proponía aplicar la correspondiente legislación para el caso de las canteras abiertas y estudios de restauración para las abando-

(13) Consideramos también que este estudio permitió vislumbrar por primera vez la posibilidad de incluir a la ZAM en la Lista del Patrimonio de la Humanidad. Así se lo hicimos ver a la entonces directora general de Patrimonio de la Junta de Castilla y León, Dña. Eloísa Wattemberg, que creemos recordar fue la primera que planteó oficialmente tal posibilidad, aunque ignoramos el alcance que entonces llegó a tener esa iniciativa. 


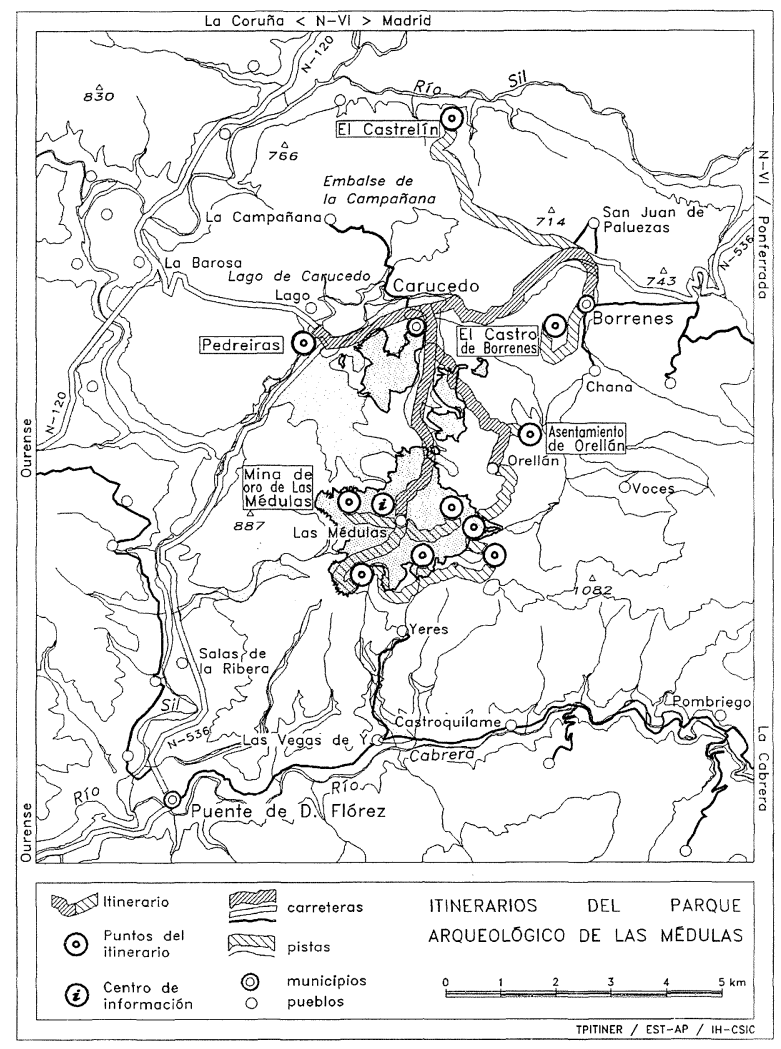

Fig. 5. Itinerarios y puntos de información del Parque Arqueológico de Las Médulas.

nadas (14), de forma que no suponía ninguna alteración para la situación existente. Por ello, consideramos que actuó el "miedo a la declaración", su visión como medida coercitiva (15). El resultado final, tras discusiones con los servicios técnicos de la Junta de Castilla y León, acabó siendo una delimitación del BIC que excedía las dimensiones de la mina, pero que rebajaba considerablemente nuestra ambiciosa propuesta (16). Sí conseguimos

(14) Sánchez-Palencia, F.J.; Fernández-Posse, M. ${ }^{2} D . ;$ Fernández Manzano, J. (dir.), con la colaboración de Orejas, A.; Álvarez, Y.; López, L.F.; Pérez, L.C.; Báez Mezquita, J.; Jular, C. y Delibes, A. (1992a): La Zona Arqueológica de Las Médulas. Estudio de viabilidad para su conversión en Parque Arqueológico. ICRBC. Ministerio de Cultura. Madrid, junio de 1992. 301 pp. autoeditadas por ordenador con 142 figs. (inédito), 144.

(15) Ese miedo es fruto sin duda de una mala información, de una visión aun mayoritaria en nuestro país, mucho más que en los de nuestro entorno más próximo, del Patrimonio como un factor estrictamente conservacionista y que puede resultar siempre un obstáculo para cualquier otro tipo de actividad, especialmente de las "desarrollistas". Por ello insistimos tanto en la conveniencia de articular discursos desde nuestro campo que sean capaces de transmitir el valor de lo patrimonial como recurso. A título de anécdota, digamos que también se levantaron voces contra la declaración que pretendían rechazar el Parque porque se iban a meter leones y tigres ( $\mathrm{sic}$ ) en Las Médulas; obviamente se trataba al menos que se incluyesen la gran mayoría de las zonas ocupadas por estériles romanos, una amplio perímetro del entorno de la mina que afectaba a diez asentamientos (2 208,2 ha en total, Fig. 3) y una delimitación individual para los dos yacimientos prerromanos de la ZAM (un perímetro separado $100 \mathrm{~m}$ respecto a su extensión real). Esta declaración quedaba teóricamente abierta a futuras ampliaciones, aun no materializadas que nosotros sepamos.

Como resultado a medio plazo de ese estudio, el equipo recibió el encargo de realizar un anteproyecto en firme tendente a la conversión de la ZAM en Parque (17). En él se establecían de forma muy concreta una serie de actuaciones, que son en esencia las que han dotado al parque del contenido que actualmente posee. Estas mediadas han sido las siguientes:

1. Itinerarios y puntos de información del Parque (Fig. 5): En el ambicioso estudio de viabilidad se contemplaban un total de 12 itinerarios vertebrados a lo largo de 31 puntos de información. Descartados en su totalidad los que afectaban a la zona 2 , el montaje actual incluye 3 itinerarios con un total de 11 puntos de información y 22 señales informativas y 12 señales de dirección instaladas (18).

Los itinerarios sólo afectan hasta ahora a las estructuras visibles más evidentes por sí mismas: la mina de oro, los dos castros prerromanos y los asentamientos romanos (aunque de estos, sólo uno ha sido señalizado) (19). Nuestra postura ha sido siem-

de una manipulación que pretendía explotar malévolamente el desconocimiento de algunas gentes.

(16) UNESCO: Convention concernant la protection du patrimoine mondial, cultural et naturel. Liste du Patrimoine Mondial. Formulaire de proposition d'inscription: Zone archéologique "Las Médulas", Espagne. Junta de Castilla y León, 1997, 2-4. Una vez producida la inclusión de Las Médulas en la Lista del Patrimonio de la Humanidad, no antes, sí surgieron algunas voces que reclamaron la extensión de la declaración del BIC hasta áreas que nosotros incluíamos en la zona 2.

(17) Sánchez-Palencia, F.J.; Fernández-Posse, MªD.; Fernández Manzano, J. y Báez Mezquita, J.A. (dir.) (1994): Parque Arqueológico de Las Médulas. Anteproyecto. Junta de Castilla y León. Dirección General de Patrimonio y Promoción Cultural. Madrid, febrero de 1994. $52 \mathrm{pp}$. autoeditadas por ordenador +19 figs. (inédito)

(18) Sánchez-Palencia, F.J.; Fernández-Posse, Mª.; Fernández Manzano, J.; Orejas, A. (redactores) (1995): Parque Arqueológico de Las Médulas. Proyecto de Señalización. Junta de Castilla y León. Consejería de Cultura y Turismo. Dirección General de Patrimonio y Promoción Cultural. Madrid, octubre de 1995. 19 págs. autoeditadas por ordenador +27 figuras CAD (encargo realizado mediante contrato entre la Junta de Castilla y León y la Universidad de Valladolid) (inédito)

(19) El yacimiento de Las Pedreiras de Lago no ha sido aun adquirido y no puede ser objeto de señalización por permanecer en manos privadas. 
pre potenciar la comprensión del paisaje cultural y del proceso histórico que representa, aunque de momento sólo se refiera a laAntigüedad, a través de su visita y explicación directa. Por ello, las señales instaladas en los puntos de información pretenden ante todo interpretar lo que el visitante esta viendo directamente a través de esquemas gráficos y un texto lo más reducido posible (Lám. I). Sólo el itinerario de la mina cuenta con tres señales que resumen los recorridos, su trazado y su duración en sus tres posibles puntos de entrada, de forma que el visitante que no se informe previamente difícilmente podrá acceder a los otros dos itinerarios (20).

2. El centro de información o aula arqueológica. El único edificio de los tres previstos en el estudio de viabilidad se halla a la entrada del pueblo de Las Médulas (21). Es de nueva planta por la imposibilidad material de rehabilitar una casa tradicional del mismo pueblo. De acuerdo con nuestra visión sobre lo que debía ser el parque, el centro se concibió esencialmente con un carácter informativo y complementario de la visita sobre el terreno, de forma que no pudiera llegar a sustituirla, sino que contribuyese a que el visitante sintiese la necesidad de ver por sí mismo lo que en él se explicaba.

En los $100 \mathrm{~m}^{2}$ aproximadamente de cada planta se desarrollan dos ideas muy claras. En la planta de arriba, la que está a la altura de la entrada, se sitúa en primer lugar el paisaje cultural de Las Médulas dentro de su contexto histórico (superando por supuesto el ámbito local) a base de mapas, maquetas y dibujos reconstructivos. La planta baja está dedicada a ofrecer otra información difícilmente mostrable sobre el terreno: los instrumentos mineros y su utilización dentro de las diversas fases del sistema de explotación. Por último, en la misma planta baja se proyecta un video sobre la ZAM.

3. La guía arqueológica. Editada dentro de la serie de guías arqueológicas de la Junta de Castilla y León (Sánchez-Palencia et alii, 1999), su con-

(20) Esta carencia está condicionada en buena parte por el mal estado de los accesos. Así pues, de momento esa información se da verbalmente en el centro de acogida, de forma que el visitante puede estar al tanto de las malas condiciones de los caminos. De cualquier modo, se trata sin duda de un problema pendiente de resolver.

(21) El autor del proyecto es el arquitecto J.M. Báez Mezquita, arquitecto de la Univ. de Valladolid especializado en el estudio de la arquitectura vernácula y colaborador en nuestro estudio de viabilidad. El equipo de investigación, con el visto bueno de los servicios técnicos de la Junta de Castilla y León, propuso las líneas esenciales del montaje didáctico, que fue ejecutado por Terra-Arqueos, s.l. Los otros dos centros que se habían previsto se encontrarían en los pueblos de Orellán y Yeres, puntos de acceso naturales a la zona por el este y oeste respectivamente.

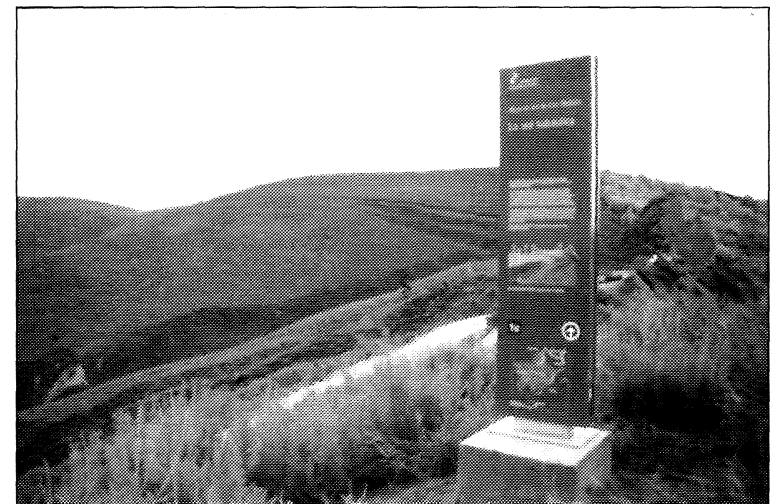

Lam. I. Una de las señalizaciones utilizadas en los puntos de información de la Zona Arqueológica de Las Médulas (León).

tenido se ha estructurado de la misma forma que los itinerarios para que el visitante no tenga problemas en su utilización; de hecho la portadilla de cada uno de sus capítulos es precisamente un plano del itinerario a seguir. Se ha puesto también especial cuidado en que el lector puede obtener una primera visión resumida y muy gráfica, ampliable en la medida de sus intereses con el texto general. Así pues, puede calificarse más como una obra de alta divulgación que simplemente como una guía en sentido estricto. También se editó un folleto en formato de tríptico (Sánchez-Palencia et alii, 1995) de contenido mucho más resumido. Por su parte la recién creada Fundación Las Médulas ha iniciado una serie de cuadernos de contenido monográfico para contribuir también a la labor de divulgación de temas directa o indirectamente relacionados con la ZAM (22).

Sobre estos tres puntos se han vertebrado hasta ahora las actuaciones de nuestro equipo para contribuir a la conversión de la ZAM en un parque arqueológico. Junto a ellas y paralelamente a su ejecución, hemos intentado transmitir y debatir nuestra visión del parque con profesionales interesados, responsables institucionales (23) y, en especial, con

(22) El primero de ellos se refiere fundamentalmente al oro y su explotación (Sánchez-Palencia et alii, 1999b) y están preparados o en estado de redacción muy avanzada otros tres sobre El Castrelín de San Juan de Paluezas, la mano de obras en las minas y Las Médulas y la literatura ilustrada y romántica.

(23) Queremos resaltar y agradecer el apoyo recibido por casi todas ellas y hacerlo extensivo a aquellas otras que discreparon de nuestra actuación con una crítica constructiva, que tan necesaria es en estos casos. No obstante, queremos destacar en especial el apoyo recibido por parte de los servicios técnicos centrales de la Junta de Castilla y León en Valladolid, responsables administrativos en último término de las intervenciones realizadas. 
las gentes de la zona. Con este objetivo concreto se han llevado a cabo dos iniciativas que queremos destacar dentro de nuestra labor didáctica y formativa. De un lado, se han realizado cinco campos de trabajo, desarrollados en la propia ZAM entre 1994 y 1999, a los que han asistido voluntariamente unas cuarenta personas del entorno con ocupaciones muy diversas, en su mayoría estudiantes universitarios o licenciados. Por otra parte, también se han impartido dos "cursos de informadores", exclusivamente destinados a los habitantes de los tres municipios en cuyos terrenos se encuentra el parque, a los que han asistido veinticuatro personas de muy diversa ocupación y formación.

\section{PERSPECTIVAS}

A modo de epílogo, quizás sea conveniente echar un vistazo a las perspectivas de futuro de la ZAM y del Parque. Es evidente que las modestas medidas tomadas hasta ahora, que no son sino un punto de partida, y sobre todo su inclusión en la Lista del Patrimonio de la Humanidad han influido en el espectacular incremento de la explotación del turismo en la zona (24). Ahora bien ese auge dista mucho de estar adecuadamente ordenado y articulado e incluso puede llegar a poner en peligro el deseable carácter duradero de tal recurso.

Uno de los principales problemas pendientes es el mantenimiento y la mejora de las infraestructuras de acceso y servicios. Aunque se han producido algunas actuaciones en este sentido, aun queda mucho por realizar hasta conseguir una de las recomendaciones del ya mencionado comité de expertos de la UNESCO: conseguir un acceso al parque que equilibre la prestación de servicios al visitante y un control que impida la masificación. Hemos de tener en cuanta que, a pesar de que no existen referencias seguras para cuantificar las visitas, puesto que no hay "entrada única", las estimaciones realizadas apuntan hacia una media superior a las 100000 personas al año, con una distribución estacional muy marcada que genera aglomeraciones en los días-punta del verano y vacaciones. Frente a una clara tendencia a mejorar los accesos hasta el extremo de que el visitante pueda llegar en coche hasta los principales puntos de información, consideramos que debe darse preferencia a una circu-

(24) Sólo a modo de ejemplo, en el mismo pueblo de Las Médulas se ha pasado en tres años de la existencia de un único bar al funcionamiento de no menos de cuatro restaurantes. lación perimetral, potenciando los aparcamientos disuasorios según ya se ha empezado a hacer.

También está pendiente la dotación de una infraestructura de personal mínima a todas luces imprescindibles para el parque; hasta el momento sólo existen una o dos personas que atienden estacionalmente el centro de información y algunos guías en la época de verano. En fin y por no extendernos más, uno de los problemas esenciales es la diversidad de administraciones implicadas en el mantenimiento y desarrollo de la ZAM: ayuntamientos, Consejo comarcal, Diputación provincial y la propia Junta de Castilla y León. Pero esa misma circunstancia puede convertirse en una ventaja si se aúnan criterios y actuaciones. A tal efecto se ha creado la Fundación Las Médulas, en la que además de los mencionados organismos oficiales están presentes entidades privadas, como patrocinadores, $y$ de investigación, caso del CSIC y la universidades de León y Valladolid. Su reciente constitución sólo ha permitido hasta ahora el desarrollo de iniciativas muy puntuales, pero su deseable consolidación puede ser uno de los instrumentos decisivos para el futuro de la ZAM y del parque.

\section{BIBLIOGRAFÍA}

ANALYSE (1995): des paysages: de la terre au ciel. Table Ronde Internationale de l'Université de Besançon (Besançon, 1993). París.

Burillo, F. (ed. y coord.) (1998): Arqueología del paisaje. Arqueología Espacial, 19-20 (Comunicaciones presentadas al $5^{\circ}$ Coloquio Internacional de Arqueología Espacial, Teruel, 1998). Teruel.

CAmBi, F. y TERrenato, N. (1994): Introduzione all'Archeologia dei Paesaggi. La Nuova Italia Scientifica. Roma.

CRIADO, F. (1993): "Límites y posibilidades de la Arqueología del Paisaje". SPAL, 2: 9-55.

Domergue, C. (1986): "Dix-huit ans de recherche (1968-1986) sur les mines d'or romaines du Nord-Ouest de la Péninsule Ibérique". Actas I Congreso Internacional Astorga Romana, 2 (Astorga, 1986): 7-101. Astorga.

- (1990): Les mines de la Péninsule Ibérique dans l'antiquité romaine. École Française de Rome. Roma.

Darvill, T.; Gerrard, C. y Startin, B. (1993): "Identifying and protecting historic landscapes".Antiquity, 67: 56374.

Darvill, T.; Sauders, A. y Startin, B. (1987): “A question of national importance: approaches to the evaluation of ancient monuments for the Monuments Protection Programme in England". Antiquity, 61: 393-408. 
Fernández-Posse, M.D.; Montero, I.; SAnChez-Palencia, F.J. y RoviRA, S. (1993): "Espacio y metalurgia en la Cultura Castreña: la ZonaArqueológica de Las Médulas". Trabajos de Prehistoria, 50: 197-220.

FERnÁndez-Posse, Ma D. y SÁnchez-PALEnCIA, F.J. (1988): La Corona y El Castro de Corporales II. Campaña de 1983 en La Corona y Prospecciones en la Cabrera y la Valdería (León). Excavaciones Arqueológicas en España, 153. Ministerio de Cultura. Madrid.

FERnÁndeZ-Posse, MåD.; SÁnChEZ-PALENCIA, F.J.; FERNÁNdez Manzano, J. y Orejas, A. (1994): "Estructura social y territorio en la Cultura Castreña prerromana". $1^{\circ}$ Congresso de Arqueologia Peninsular. Actas, IV (Porto, 1993): Trabalhos de Antropologia e Etnologia, 34, 3-4: 191-212. Porto.

Galván, V.; Fernández-Posse, MªD.; SÁnchez-Palencia. F.J. y GALVÁN, J. (1993): “Tipos cerámicos y geoquímica: El Castrelín de San Juan de Paluezas (León)". Archivo Español de Arqueología, 66: 248-257.

Gil y CARrasco, E. (1985): Bosquejo de un viaje a una provincia del interior (edición de M. ${ }^{a}$ Paz Díez Taboada). Diputación Provincial de León. León.

McGlaDE, J. (1995): "Archaeology and the ecodynamics of human-modified landscapes". Antiquity, 69: 113-132.

Olmos, R. (e.p.): "La arqueología y el paisaje del Bierzo en los escritores ilustrados y románticos”. En F.-J. Sánchez-Palencia (ed.): Las Médulas (León). Un paisaje cultural en la Asturia Augustana. Instituto Leonés de Cultura. León (publicación prevista en el 2000)

OrejAs, A. (1991): "Arqueología del paisaje. Historia, problemas y perspectivas". Archivo Español de Arqueologia, 64: 191-230.

- (1995): "Arqueología del paisaje: de la reflexión a la planificación”. Archivo Español de Arqueología, 68: 215-224.

- (1996): Estructura social y territorio. El impacto romano en la Cuenca Noroccidental del Duero. Anejos de Archivo Español de Arqueología, XV. CSIC. Madrid.

- (1998): "El estudio del Paisaje: visiones desde la Arqueología". En F. Burillo (ed. y coord.): Arqueología del Paisaje, Arqueología Espacial, 19-20: 9-19.

Orejas, A.; Plácido, D.; Sánchez-Palencia, F.J.y FernánDEZ-Posse, MªD. (1999): "Minería y Metalurgia: de la Protohistoria a la España romana". Studia Historica. Historia Antigua, 17, Estudios de economía antigua en la Península Ibérica. Nuevas aportaciones: 263-298.

Pérez Garcia, L.C. y SÁnchez-PAlencia, F.J. (1992): "Los yacimientos de oro de Las Médulas de Carucedo (León)". En J. García Guinea y J. Martínez Frías (coords.): Recursos minerales de España. CSIC. Madrid: 861-873.

Prada BengOA, J.I. DE (1994): "La inclusión de los bienes culturales en la lista del Patrimonio Mundial. Criterios y procedimiento vigente". Boletín Informativo. Comisión española de la UNESCO, Octubre-Diciembre: $15-21$.
- (1995a): "Hacia una estrategia global para la protección del patrimonio mundial". Boletín Informativo. Comisión española de la UNESCO, Enero-Marzo: 11-15.

- (1995b): "Efectos de la inscripción de bienes culturales en la lista del patrimonio de la Humanidad". Boletín Informativo. Comisión española de la UNESCO, Abril-Junio: 9-15.

Querol, M.A. (1995): "Patrimonio cultural y patrimonio natural: ¿ una pareja imposible?”. Homenaje a la Dra. D. ${ }^{a}$ Milagros Gil-Mascarell Boscà. Extremadura Arqueológica, 5: 301-306.

SÁnchez-Palencia, F.J. y Fernández-Posse, Ma D. (1985): La Corona y El Castro de Corporales I (Truchas, León). Excavaciones Arqueológicas en España, 141. Madrid: 1-388.

SÁncheZ-Palencia, F.J.; Fernández-Posse, MaaD.; Fernández Manzano, F.J.; Alvarez González, Y. y LóPez GoNZÁLEZ, L.F. (1990): "La ZonaArqueológica de Las Médulas (1988-89)".Archivo Español deArqueología, 63: 249-264.

Sánchez-Palencia, F.J.; Fernández-Posse, MªD.; Orejas, A. y Pérez García, L.C. (1992): "Las Médulas de Carucedo (León): sistemas de explotación en laAntigüedad». III Congreso Geológico de España y VIII Congreso Latinoamericano de Geología, 3 (Salamanca, 1992): 339-346. Salamanca.

Sánchez-Palencia, F.J.; Fernández-Posse, Maad. y FerNÁNDEZ MANZANO, J. (1994a): "La Zona Arqueológica de Las Médulas". $6 .^{\circ}$ Congreso Hispano-Ruso de Historia. Fundación Cultural Banesto. Madrid: 123141.

Sánchez-Palencia, F.J.; Orejas, A. y Fernández-Posse, $M^{a} D$. (1994b): "La mano de obra en la minería romana del Noroeste Peninsular". $1 .^{\circ}$ Congresso de Arqueologia Peninsular. Actas, IV (Porto, 1993): Trabalhos de Antropologia e Etnologia, 34, 3-4: 243258.

SÁnchez-Palencia, F.J. y Orejas, A. (1994): "La minería de oro del noroeste peninsular. Tecnología, organización y poblamiento". En D. Vaquerizo Gil (coord.): Metalurgia en la España prerromana y romana. Diputación Provincial de Córdoba. Córdoba: 147-233.

Sánchez-Palencia, F.J.; Fernández-Posse, MãD. y FerNÁNDEZ ManZANo, J. (1995): Las Médulas. León. Zona Arqueológica. Folleto informativo en $16 \mathrm{pp}$. (versiones en español, francés e inglés). Junta de Castilla y León. Valladolid.

Sánchez-Palencia, F.J.; Fernández-Posse, MåD.; Fernández Manzano, J.; Orejas, A.; Álvarez González, Y; LÓPEZ GonzÁlez, L.F. y Pérez GARCía, L.C. (1996): "Las Zonas Arqueológicas como Paisajes Culturales: el Parque Arqueológico de Las Médulas (León)”. Homenaje a Manuel Fernández Miranda: Complutum Extra, 6, II: 383-403.

SÁnchez-Palencia, F.J.; Fernández-Posse, MaaD.; Fernández Manzano, J. y Orejas, A. Con la colaboración de 
Alvarez, Y.; LóPez, L.F.; Pérez, L.C.; Jular, C. y MoRENO, E. (1999a): La zona arqueológica de Las Médulas (León). Guía arqueológica. Junta de Castilla y León. Salamanca. 2. ${ }^{\text {e }}$ d. (1. $\left.{ }^{\mathrm{a}}, 1996\right)$

Sánchez-Palencia, F.J.; Pérez, L.C. y Orejas, A. (1999b): El Oro de Las Médulas. Fundación Las Médulas. Ponferrada.
SEMINARIO (1993): de Parques Arqueológicos (Madrid, 1989). Ministerio de Cultura. Madrid.

VICENT, J.M. (1991): "Fundamentos teórico-metodológicos para un programa de investigación arqueológica". En P. López (ed.): El cambio cultural del IV al II milenios a.C. en la comarca Noroeste de Murcia. CSIC. Madrid: 29-117.

T. P., 57, n. $^{\circ} 2,2000$ 